\title{
O ESTUDO DE CASO DO IMPACTO DO SISTEMA DE TRANSFERÊNCIA DE RESERVAS (STR) NA REDUÇÃO DE CUSTO DE SERVIÇOS LOGÍSTICOS DE NUMERÁRIO
}

\section{THE CASE STUDY OF THE IMPACT OF THE RESERVATION TRANSFER SYSTEM (STR) ON COST REDUCTION OF NUMERARY LOGISTICS SERVICES}

\author{
Francisco José de Souza - franciscosouza2005@gmail.com \\ Paulo Henrique Benedeti - paulohbenedeti@gmail.com \\ Karla Raquel Rosa - k.r.rosa@outlook.com \\ Oswaldo Lázaro Mendes - Oswaldo.lazaro@fatectq.edu.br \\ Faculdade de Tecnologia de Bebedouro (FATEC) - SP - Brasil
}

DOI: 10.31510/infa.v15i1.369

\section{RESUMO}

O presente trabalho mostrará o funcionamento do sistema da cadeia de suprimento da logística de numerário com propósito de indicar, através de uma pesquisa exploratória e qualitativa de estudo de caso com embasamento bibliográfico e levantamento de dados, o quanto é possível uma empresa de prestação de serviços bancários explorar o sistema de transferência de reservas (STR) para a redução de custos mediante realizações de interbancários com instituições financeiras parceiras. Considerando as exigibilidades do atual mercado, o artigo explicita o cenário dotado de tarifas, normas, regras, condições e variáveis que são impostas tanto pelas transportadoras de valores quanto pelo Sistema Financeiro Nacional (SFN) que dificultam o gerenciamento de uma tesouraria de numerário e consequentemente da gestão de recursos da instituição bancária.

Palavras-chave: Numerário. Transferência. Interbancário.

\begin{abstract}
The present work will show the operation of the supply chain system of cash logistics with the purpose of indicating through a case study how much it is possible for a banking service company to exploit the system of transfer of reserves (STR) for the reduction of cost by means of interbank in relation to another possibility that is made by the custodian bank with transactions of supply and collection in the circulating medium. Considering the demands of the current market that originates from a large demand of bank customers to move in cash, the article contemplates the rates and conditions imposed by the securities carriers and the rules and regulations of the National Financial System (SFN) overcomes a surprising result when it comes to corporate management of cost and finances.
\end{abstract}

Keywords: Cash. Transfer. Interbank. 


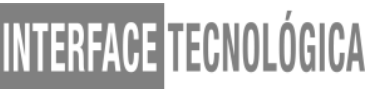

\section{INTRODUÇÃO}

O desenvolvimento da cadeia de suprimento de numerário difundida como Meio Circulante cresce em média 5,86\% ao ano de acordo com informações do Banco Central do Brasil (2017) o que transmite uma contra posição significativa considerando que a Federação Brasileira de Bancos (2015) confirma que cerca de 50\% das transações financeiras são realizadas através de meios digitais de canais de alto atendimento.

O crescimento da circulação de numerário no país fomenta a representatividade e seriedade dos assuntos correlacionados como transporte, segurança, risco e atendimento de demanda. Estes fatores acarretam em uma grande dificuldade para a execução e controle da logística de numerário que contam com diversos vieses como custos, tarifas, legislações, normas, treinamento qualificado e ferramentas de gestão. O trabalho explanará no intuito de demonstração prática com dados reais, sobre o embasamento de um estudo de caso de um banco de pequeno porte da capital do estado de São Paulo, quais os custos acarretados que uma instituição financeira possui ao transacionar valores seja pelo sistema de liquidação Sistema de Transferência de Reservas (STR) através de parcerias com outras instituições financeiras bancárias ou pelo Meio Circulante (MeCir) exclusivamente pelo banco custodiante, que são fundamentais para a operação logística de valores e consequentemente para o atendimento das demandas dos clientes bancários.

\section{FUNDAMENTAÇÃO TEÓRICA}

A publicação de trabalhos acadêmicos no ramo da logística de numerário são relativamente escassos devido a dificuldade de se conseguir extrair das instituições envolvidas dados para seus desenvolvimentos. Quando conseguem informações são realizados pelas próprias instituições bancárias ou seus funcionários, que são responsáveis do transporte de valores, ou pela Federação Brasileira de Bancos - FEBRABAN ou pelo Banco Central do Brasil - BACEN. Ainda assim, encontra-se fragmentos em sites qualificados, que permite montar uma linha de raciocínio para embasar uma exploração deste nicho do Sistema Financeiro Nacional (SFN). 


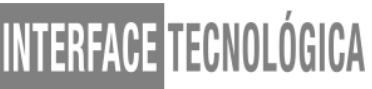

\subsection{Logística empresarial}

A economia atualmente vem sendo desenvolvida crucialmente pelo dinamismo empresarial, que procura de forma incisiva e persistente priorizar o atendimento ao cliente, promovendo a geração de renda com crescimento financeiro e para isso torna-se necessário o melhoramento e aperfeiçoamento dos estudos a realizar as atividades e rotinas empresarias de modo mais eficiente e eficaz (ENDEAVOR, 2015). Maximiano (2009) discorre que o desenvolvimento de conhecimentos da Administração surgiram gradualmente, tendo como ponto inicial a Administração Cientifica instituída por Frederick Winslow Taylor (1856-1915) que em 1903 publicou o Shop management que contém assuntos sobre os conceitos daquela percepção: 1) ganho produtivo e boa distribuição de salários; 2) análises para melhorar a cumprimento de trabalhos; 3) exercício e escolha de empregados; 4) colaboração e comunhão entre dirigentes e trabalhadores. Ocorrendo assim a mesma percepção evolutiva para os pilares da administração contemporânea como na Operações ou Produção, Marketing, Finanças, Gestão de Pessoas, Pesquisa e Desenvolvimento e Tecnologia da Informação com a mesma intensidade e predestinação.

Os pilares administrativos tradicionais, anteriormente descritos, foram propulsores para o surgimento de um estudo sobre uma gestão integrada conhecida como logística empresarial. Por mais antigo que seja as atividades de transporte e estocagem, a logística empresarial é considerada uma ciência recém estruturada, consagrada como uma administração coordenada e colaborativa de exercícios inter-relacionadas (BALLOU, 2006).

Segundo os códigos de 1962 do Council of Logistics Management (apud BALLOU, 2006):

Logística é o processo de planejamento, implantação e controle do fluxo eficiente e eficaz de mercadorias, serviços e informações relativas desde o ponto de origem até o ponto de consumo com o propósito de atender às exigências dos clientes".

A percepção da dimensão abrangida pela logística empresarial e de qual forma esta ciência se relaciona com outras áreas da administração compreende que esta inter-cooperação vincula logística a diversas estruturas e segregações organizacionais. Sendo encontrados em empresas industriais, de agronegócio, no terceiro setor (ongs e instituições filantrópicas) e nas prestadoras de serviços como nas instituições financeiras que prestam serviços bancários, alvo do presente trabalho (BALLOU, 2006). 


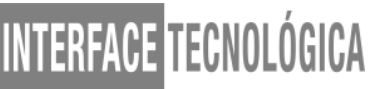

\subsection{Logística nas instituições financeiras}

Pela FEBRABAN (2017) os bancos, cooperativas e instituições financeiras de prestação de serviço bancário possuem uma estrutura física enquadradas como escritório de serviços gerais constituídas por bancadas de mesas com inúmeros computadores, cadeiras e muita papelada, com apenas um diferencial, que são tesoureiros eletrônicos, contadoras de cédulas ou ATMs- Automatic Teller Machine (Caixas Eletrônicos) e os operadores de caixa que executam as transações de forma "manual". Assim conota-se a logística empresarial de modo modesto por não haver grandes transações de mercadorias ou de produtos propriamente observado, mas sim um tráfego constante de informações que transitam no meio digital (mensagens, e-mail, transferências, imagens, documentos digitalizados) e também no meio físico documental (papéis e documentos impressos, timbrados, assinados, cartas, mala-direta, cheques, cartões, fichas de compensação e dinheiro). Observa-se uma grande importância para a atividade fim dessas empresas as compensações, liquidações de títulos que ocorrem por meio do Sistema de Pagamento Brasileiro - SPB e suas clearing house (casas de compensação, ex CETIP, BMF\&BOVESPA, SELIC, entre outras), (BACEN, 2017). E a mais visível forma de logística existentes nos bancos e cooperativas de crédito, são as transações de suprimento e recolhimento que envolvem numerário, justamente por haver todo o transporte, roteirização, manuseio, prazo, modalidade e intermodalidade, e custos operacionais elevados.

\subsubsection{A logística no meio circulante}

São estruturados como rede de suprimento e recolhimento de numerário para os clientes bancários, as agências, que são instituídas como Postos de Atendimento Bancário PABs, os Postos de Atendimento Eletrônicos - PAEs, definidos como financeiras e correspondentes varejistas do comércio geral que por sua necessidade de demanda de numerário, consegue em união com o banco comercial, acesso as transportadoras de valores e assim ficam vinculados ao Banco do Brasil, que é nomeado pelo Banco Central do Brasil BACEN como o único banco custodiante nacional que é representada pela Figura 1 (OKINO, 2010). 
Figura 1 - Meio Circulante

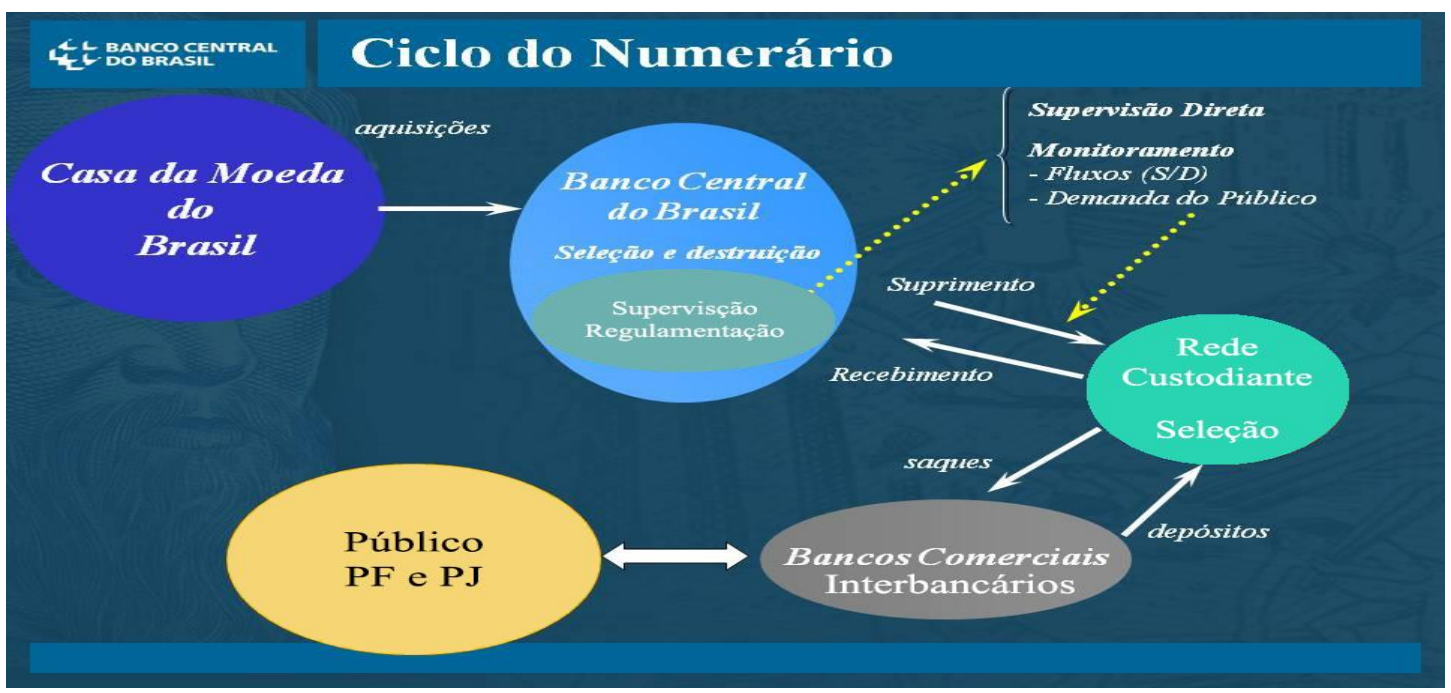

Fonte: adaptado de Banco Central do Brasil (2017)

\subsubsection{O meio circulante no mundo digital}

Para conseguir estabelecer um bom nível de comunicação no meio circulante foi gerada a necessidade de desenvolver sobre o Sistema de Pagamento Brasileiro (SPB) um box comunicativo que permite segurança, credibilidade, menor ruídos ou falhas tecnológicas ou de comunicação, e que houvesse tamanha versatilidade para todos os integrantes/usuários desta cadeia. Para tanto, desenvolveu-se uma mensageria conhecida no Grupo de Serviços do Sistema de Transferência de Reservas (STR) como CIR - Meio Circulante e é por este canal que as instituições financeiras bancárias conseguem gerenciar suas demandas de numerário, remuneração à prestação de serviço do custodiante, cédulas supostamente falsas, cédulas manchadas com dispositivos antifurto, cédulas dilaceradas ou mutiladas ou meio entre outras consultas e ajustes devidos ao banco custodiante Banco do Brasil. Dentre todas as possibilidades acatar-se-á para este trabalho as transações à dizer: 1) CIR0003 - IF requisita Saque de numerário: transferência que requer numerário para o banco custodiante que deverá ser agendada com $48 \mathrm{~h}$ de antecedência garantido ou com menos de $48 \mathrm{~h}$ de acordo com a disponibilidade do BB, nesta mensagem contém o encargo de remuneração do custodiante; 2) CIR0005 - IF requisita Depósito de numerário: transferência que solicita autorização para despacho de numerário para o Banco do Brasil, local e datas são informados, assim como a remuneração do BB e apresentando diferença a instituição é avisada na mesma mensagem (SFN, 2016). 


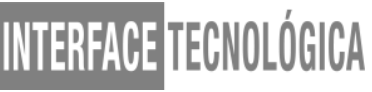

Para esta prestação de serviço o Banco do Brasil tem o direito de exercer cobrança de $0,16 \%$ (dezesseis centésimos por cento) sobre o valor transacionado (BACEN, 2016).

\subsubsection{Transporte de valores e seus custos}

No país a percepção da necessidade de ter um intermediário para o transporte de valores teve início em 1965 por conta de um assalto denominado "Assalto dos Gregos" com danos de 500 mil dólares na capital São Paulo, o valor estava sendo transportado por um carro utilitário do Banco Moreira Salles, valor exorbitantemente alto para a época. Após este ocorrido contataram a empresa norte americana Brink's Incorporated que se instalou no mesmo ano (DOTTA apud OKINO, 2010).

Consolida-se as configurações de chamado e seus preços, sendo as solicitações: 1) Eventual - solicitação para atendimento agendado com 01 dia de antecedência sendo recolhimento ou suprimento; 2) Especial - solicitação para atendimento agendado no mesmo dia, com 03 horas de antecedência ou salvo a disponibilidade da transportadora; 3 ) Rotineiro são atendimento programados estipulados em acordo pré-fixado pelo meio da precisão do cliente.

Os preços específicos são informados pela transportadora no ato da contratação com influência na negociação a distância, o volume, quantidade de agências para atendimento, entre outros limites da transportadora como também demais necessidades dos clientes. Ainda acompanhando o sistema de faturamento e das transportadoras, tem-se as cobranças das consequentes tarifas: a) Custódia - é uma tarifa cobrada diariamente numa média de 0,014\% sobre os valores pernoitados; b) Ad-valorem - alíquota que recorre sobre os valores transitados em carro forte sendo de um valor estimado de 0,07\%; e c) Processamento - tarifa cobrada por milheiro processado nas bases regionais da transportadora negociado diretamente com cada cliente de acordo com a demanda proposta. (BENEDETI, 2017).

\subsection{O sistema de transferência de reservas (STR)}

Este sistema permite a existência de meio eletrônico de liquidações online em tempo real, transferência de fundos de um participante para outro chegando até o consumidor final, os clientes bancários pessoas físicas e jurídicas das instituições financeiras. Foi criado a Circular 3.100, de 28 março de 2002 e gerenciado exclusivamente pelo Banco Central do 


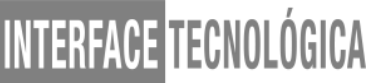

Brasil pelo Departamento de Operações Bancárias e de Sistema de Pagamentos - DEBAN (BACEN, 2017). Ainda sobre a perspectiva da Circular 3.100 que tem a capacidade de funcionamento contínuo e seguro com $99,8 \%$ de margem de assertividade operacional, em todos os dias úteis das $06 \mathrm{~h} 30$ às $18 \mathrm{~h} 30$ (horário de Brasília) e para liquidações para conhecimento dos clientes das instituições financeiras bancárias o horário máximo para registros até às $17 \mathrm{~h} 30$, o que confirma a possibilidade de uma melhor e abrangente margem de atendimento e acesso, ficando mais equivocado considerando e comparando com o horário do atendimento dos bancos comerciais das 09:00 às 15:00.

No âmbito deste sistema o trabalho envolverá apenas uma das mensagens possíveis que caracteriza-se nas transações de numerário: STR0003 - IF requisita Liquidação de transferência de numerário, sendo suas particularizações pelo Catálogo de Serviços do SFN (2016) admitir que instituições financeiras (IF) dê cumprimento as transferências digitais para permuta de numerário por intervenção das transportadoras (BACEN, 2017).

\section{PROCEDIMENTOS METODOLÓGICOS}

Para o desenvolvimento do presente artigo foram utilizadas pesquisa bibliográfica e a metodologia de estudo de caso. O objetivo da pesquisa bibliográfica, conforme citado por Seltiz (1967), é buscar maior intimidade com o assunto estudado (apud GIL, 2002).

O método do estudo de caso é um meio de organizar dados sociais preservando o caráter unitário do objeto social estudado, além de ser considerado um tipo de análise qualitativa. (Goode e Hatt, 1969). Segundo Yin (1989) o estudo de caso é uma averiguação baseada na experiência, que investiga um fenômeno dentro de um contexto real. Para Yin (1989), a escolha pela metodologia de estudo de caso deve ser feita, principalmente, em pesquisas que buscam expor os comportamentos relevantes que não podem necessariamente, ser manipulados, mas faz-se possível, desenvolver observações sistemáticas.

O estudo contempla um Banco de pequeno porte da capital do estado de São Paulo, que por questões de segurança da informação e sigilo de dados, não permitiu a divulgação da imagem jurídica. Os levantamentos dos dados foram obtidos através do contato com o gestor da tesouraria do referido banco devido a influência e parceria do pesquisador, onde conseguiu-se acesso aos relatórios, ao faturamento do banco junto a transportadora de valores prestadora de serviço e as informações complementares repassadas por e-mail. Agrupadas estas informações e elementos geraram as tabelas que compõem o banco de dados do artigo. 


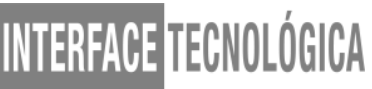

Não sendo divulgados tais documentos procurando proteger as políticas de segurança da informação e o sigilo acordado com o representante da instituição.

\section{RESULTADOS E DISCUSSÃO}

Em suma a pesquisa apanhará os dados coletados e fará um base comparativa das transações realizadas pelo banco a saber qual o custo obtido, através de simulação, caso o banco tivesse feito apenas interbancário ou caso tivesse ocorrido apenas com transferências junto ao banco custodiante, afim de comprovar a diferença no custo que gera a realizações de parcerias com bancos diversos deixando para eventos excepcionais (quando o mercado não consegue aderir e absorver os altos e baixos das demandas) a necessidade do Banco do Brasil.

A tabela abaixo exemplifica a diferenciação e o cenário entre executar transações com bancos parceiros (interbancários) ou junto ao banco custodiante (Banco do Brasil):

\section{Tabela 2 - Diferenciação: Banco Custodiante CIR x Banco Parceiro STR}

\begin{tabular}{|c|c|c|c|c|}
\hline \multicolumn{5}{|c|}{ Diferenciação: Banco Custodiante CIR x Banco Parceiro STR } \\
\hline Modalidade & Banco Custodiante & Observação: & Banco Parceiro & Observação: \\
\hline Transação & CIR0003 e CIR0005 & $\begin{array}{l}\text { 03-Saque e 05- } \\
\text { Depósito }\end{array}$ & STR0008 & $\begin{array}{c}\text { Envio/saque, } \\
\text { Recebido/depósito }\end{array}$ \\
\hline Custo/Tarifa & $0,16 \%$ & Sobre o valor ( $R \$$ ) & $\mathrm{R} \$ 5,00$ & Valor para saque \\
\hline Atendimento & Obrigatório & $\begin{array}{l}\text { Regulamentado } \\
\text { pelo BACEN }\end{array}$ & Não obrigatório & $\begin{array}{c}\text { Depende de ambas } \\
\text { as partes }\end{array}$ \\
\hline $\begin{array}{l}\text { Serviço de } \\
\text { Transporte }\end{array}$ & $\begin{array}{c}\text { Eventual/Especial, } \\
\text { Advalorem/Custódia } \\
\text { Processamento }\end{array}$ & $\begin{array}{c}\text { Da transportadora } \\
\text { até o BB }\end{array}$ & Custódia & $\begin{array}{c}\text { O numerário não sai } \\
\text { da Regional }\end{array}$ \\
\hline
\end{tabular}

Fonte: adequado de Benedeti (2017).

A Tabela 3 reflete o fluxo de transações realizadas pelo banco estudado, sendo esta elabora com informações reais extraídos dos relatórios e documentos do banco de pequeno porte paulista: 


\section{WTEREFAEETEECNOLOGGCA}

Tabela 3 - Fluxo de transações realizadas - Banco de Pequeno Porte Capital SP.

\begin{tabular}{|c|c|c|c|c|}
\hline \multicolumn{5}{|c|}{ Fluxo das transações realizadas - Banco de Pequeno Porte da Capital SP } \\
\hline \multirow{2}{*}{ Data da Transação } & \multicolumn{2}{|c|}{ Interbancário } & \multicolumn{2}{|c|}{ Mecir } \\
\hline & Saque & Depósito & Saque & Depósito \\
\hline 05/01/2018 & & R\$ $3.000 .000,00$ & & \\
\hline 08/01/2018 & & $\mathrm{R} \$ \quad 1.500 .000,00$ & & \\
\hline $16 / 01 / 2018$ & & & & $\mathrm{R} \$ 22.000 .000,00$ \\
\hline $23 / 01 / 2018$ & & $\mathrm{R} \$ \quad 800.000,00$ & & \\
\hline $29 / 01 / 2018$ & & $\mathrm{R} \$ \quad 2.200 .000,00$ & & \\
\hline $05 / 02 / 2018$ & & $\mathrm{R} \$ \quad 1.100 .000,00$ & & \\
\hline $08 / 02 / 2018$ & $\mathrm{R} \$ \mathbf{7 0 0 . 0 0 0 , 0 0}$ & & & \\
\hline $15 / 02 / 2018$ & & & & $\mathrm{R} \$ \quad 5.000 .000,00$ \\
\hline $19 / 02 / 2018$ & & $\mathrm{R} \$ \quad 900.000,00$ & & \\
\hline $27 / 02 / 2018$ & & $\mathrm{R} \$ \quad 3.100 .000,00$ & & \\
\hline $05 / 03 / 2018$ & & & $\mathrm{R} \$ 1.500 .000,00$ & \\
\hline $12 / 03 / 2018$ & & $\mathrm{R} \$ \quad 4.300 .000,00$ & & \\
\hline $14 / 03 / 2018$ & & $\mathrm{R} \$ \mathbf{7 0 0 . 0 0 0 , 0 0}$ & & \\
\hline $19 / 03 / 2018$ & & & & $\mathrm{R} \$ \quad 4.700 .000,00$ \\
\hline $23 / 02 / 2018$ & & 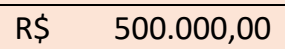 & & \\
\hline $26 / 03 / 2018$ & & $\mathrm{R} \$ \quad 1.100 .000,00$ & & \\
\hline $02 / 04 / 2018$ & $\mathrm{R} \$ \quad 500.000,00$ & & & \\
\hline $04 / 04 / 2018$ & & & $\mathrm{R} \$ 2.000 .000,00$ & \\
\hline $11 / 04 / 2018$ & & & & $\mathrm{R} \$ \quad 4.900 .000,00$ \\
\hline $20 / 04 / 2018$ & & $\mathrm{R} \$ \quad 2.300 .000,00$ & & \\
\hline $24 / 04 / 2018$ & & $\mathrm{R} \$ \quad 900.000,00$ & & \\
\hline $30 / 04 / 2018$ & & $\mathrm{R} \$ \quad 3.100 .000,00$ & & \\
\hline Totais & $\mathrm{R} \$ 1.200 .000,00$ & $\mathrm{R} \$ 25.500 .000,00$ & $\mathrm{R} \$ 3.500 .000,00$ & $\mathrm{R} \$ 36.600 .000,00$ \\
\hline
\end{tabular}




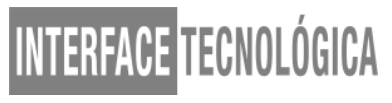

\begin{tabular}{|r|l|l|l|l|}
\hline $\begin{array}{r}\text { Quantidade de } \\
\text { Transações }\end{array}$ & 2 & 14 & 2 & 4 \\
\hline
\end{tabular}

Fonte: elaborado pelo autor com base na entrevista com representante do banco pesquisado.

Afim de demonstrar os resultados obtidos de forma claro e visualmente simplificada foi desenvolvida a seguinte tabela:

Tabela 4 - Resultados obtidos sobre os dados da empresa apresentada

\begin{tabular}{|c|c|c|c|c|c|}
\hline \multicolumn{6}{|c|}{ Resultado de Suprimento/Recolhimento - Cenários Variados } \\
\hline \multirow{2}{*}{$\begin{array}{l}\text { Implicadores } \\
\text { Situação }\end{array}$} & \multirow{2}{*}{$\begin{array}{c}\text { Todos Via Banco } \\
\text { Custodiante } \\
-\end{array}$} & \multirow{2}{*}{$\begin{array}{c}\text { Todos via } \\
\text { Interbancário }\end{array}$} & \multicolumn{3}{|c|}{ Fluxo Real } \\
\hline & & & Interbancário & Banc & Custodiante \\
\hline $\begin{array}{l}\text { Valor (R\$) } \\
\text { Movimentado }\end{array}$ & $\begin{array}{c}\mathrm{R} \$ \\
66.800 .000,00\end{array}$ & $\begin{array}{c}\mathrm{R} \$ \\
66.800 .000,00\end{array}$ & $\begin{array}{c}\mathrm{R} \$ \\
26.700 .000,00\end{array}$ & $\mathrm{R} \$$ & $100.000,00$ \\
\hline $\begin{array}{l}\text { Tarifa Banco do } \\
\text { Brasil }(0,16 \%)\end{array}$ & $\begin{array}{c}\mathrm{R} \$ \\
106.880,00\end{array}$ & Não & Não & $\mathrm{R} \$$ & $64.160,00$ \\
\hline $\begin{array}{l}\text { Tarifa da } \\
\text { Transferência STR } \\
\text { (Aproximado) }\end{array}$ & Não & $\begin{array}{c}\mathrm{R} \$ \\
55,00\end{array}$ & $\begin{array}{c}R \$ \\
40,00\end{array}$ & & Não \\
\hline $\begin{array}{l}\text { Tarifa Custódia } \\
\text { Transportadora } \\
(0,014 \%)\end{array}$ & $\begin{array}{c}\mathrm{R} \$ \\
9.352,00\end{array}$ & $\begin{array}{c}\mathrm{R} \$ \\
9.352,00\end{array}$ & $\begin{array}{c}\mathrm{R} \$ \\
3.738,00\end{array}$ & $\mathrm{R} \$$ & $5.614,00$ \\
\hline $\begin{array}{l}\text { Tarifa Advalorem } \\
\text { de Transporte } \\
(0,07 \%)\end{array}$ & $\begin{array}{c}\mathrm{R} \$ \\
46.760,00\end{array}$ & Não & Não & $\mathrm{R} \$$ & $28.070,00$ \\
\hline $\begin{array}{l}\text { Processamento de } \\
\text { Cédulas } \\
\text { Transportadora }\end{array}$ & Sim & Não & Não & & Sim \\
\hline $\begin{array}{l}\text { Transporte de } \\
\text { Valores - } \\
\text { Quantidade }\end{array}$ & 22 & Não & Não & & 6 \\
\hline Total de Custos & $\mathbf{R} \mathbf{S}$ & $\mathbf{R} \$$ & $\mathbf{R} \mathbf{S}$ & $\mathbf{R} \$$ & $97.844,00$ \\
\hline
\end{tabular}




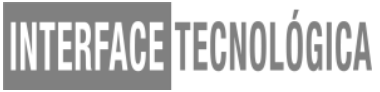

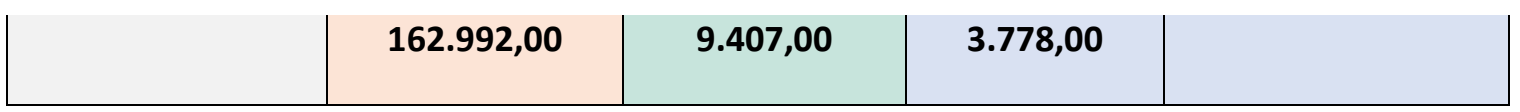

Fonte: elaborado pelo autor.

O resultado obtido no trabalho é extraordinariamente impressionante considerando o pequeno período analisado, transações realizadas pelo banco de janeiro a abril de 2018.

Observa-se uma elevada redução de custo quando as transações são redirecionadas da possibilidade de execução do Banco do Brasil (banco custodiante) para a parcerias com outros bancos comerciais (interbancários) um montante reduzido de $\mathrm{R} \$ 153.585,00$. Porém é compreensivo que não é possível conseguir executar todas as movimentações interfinanceiras por intermédio de interbancário, pois o jogo é apresentado pelo mercado e suas projeções de demanda e sazonalidades. Desta maneira o banco analisado obtém um bom trabalho em procurar transcorrer o máximo valor possível para os parceiros bancários e apenas a falta ou sobra excedente direcionar ao banco custodiante. Com este manuseio o banco conseguiu um direcionamento de 26,7 milhões de reais para os interbancários incidindo uma redução de $\mathrm{R} \$$ 61.370,00 no primeiro quadrimestre do ano.

Avantajando o resultado observado destaca-se que o interbancário não exige a movimentação de numerário por parte das transportadoras e a participação via banco custodiante exige logística de numerário o que encarece os processos de tesouraria. Este resultado econômico não foi possível calcular, pois o banco não abriu as informações sobre os custos do chamado e processamento para não expor suas negociações junto a transportadora que os fornece e para não fragilizar a segurança da informação necessária.

\section{CONSIDERAÇÕES FINAIS}

O estudo de caso mostrou-se uma ferramenta muito eficiente para destacar os resultados obtidos, a possibilidade de usar dados reais com certeza fomenta uma experiência acadêmica e profissional diferenciada. Faz saber que um trabalho acadêmico alinha as intenções das empresas em pesquisa e desenvolvimento e que poderá conotar uma possibilidade e análise periódica para o banco estudado e para outros interessados do meio.

Fica claro a importância de um acompanhamento metódico sobre a tesouraria e logística de numerário de um banco, mesmo que seja uma instituição de pequeno porte, pois os resultados impactam diretamente nos custos diretos da empresa que podem elevar os 


\section{WTEERFAET TECNOLLGGCA}

ganhos e diminuir perdas financeiras não explícitas aos olhos leigos. Por fim, a ferramenta de transferências de reservas, o STR, fará diferença para a aferição dos lucros da instituição.

\section{REFERÊNCIAS}

ABTV - ASSOCIAÇÃO BRASILEIRA DE EMPRESAS DE TRANSPORTE DE VALORES. Disponível em: <http://www. abtv-online.com.br>. Acesso em: 11 mar. 2017. $12 \mathrm{~h} 35$.

BALLOU, R.H. Gerenciamento da cadeia de suprimentos/logística empresarial. $5^{\mathrm{a}}$ ed. Porto Alegre/SC: Bookman, 2006.

BENEDETI, P. H. A utilização do sistema de transferências de reservas (str) e o impacto na redução de custos na logística de numerário. São Paulo/SP: FATECLOG, 2017.

BCB - BANCO CENTRAL DO BRASIL. Composição e segmentos do Sistema Financeiro Nacional. Disponível em: <http://www.bcb.gov.br/pre/composicao/composicao.asp>. Acesso em: 21 jan. 2017. 13 h00.

\section{. Carta circular no 3.795 de 16 de dezembro de 2016.}

Visão geral do sistema de pagamentos brasileiro. Disponível em: < http://www.bcb.gov.br/htms/novaPaginaSPB/VisaoGeralDoSPB.asp>. Acesso em: 05 mar. 2017. $18 \mathrm{~h} 30$.

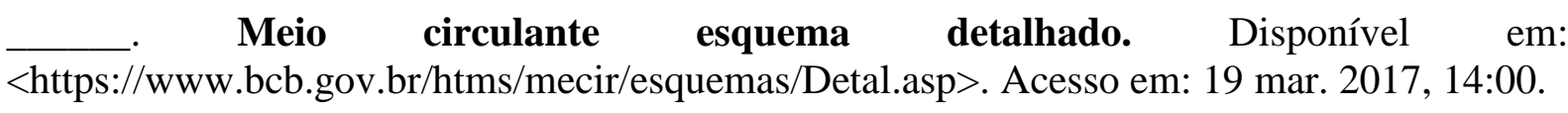

FAQ - Atendimento bancário (fila, feriados e outros). Disponível em:<http://www.bcb.gov.br/pre/bc_atende/port/servicos4.asp\#1>. Acesso em: 22 mar 2017, 23:15.

- Sistema de transferência de reservas - STR. Disponível em: < https://www.bcb.gov.br/htms/NovaPaginaSPB/STR.asp>. Acesso em:

19 mar. 2017. 19h05.

Comitê Gestor da Comunicação Eletrônica de Dados no Âmbito do SFN. Catálogo de serviços SFN. Brasília/DF, volume 1, versão 4.09, 2016.

Disponível em: <http://www.bcb.gov.br/sfn/ced/Catalogo_de_Servicos_do_SFN_Volume_I_Versao_409.pdf >. Acesso em: 29 mar. 2017 13h51.

ENDEAVOR - Empreender para empreendedores. Ferramentas de gestão. Diponível em: <https://endeavor.org.br/ferramentas-de-gestao/>. Acesso em: 01 mai. 2018 18h00. 


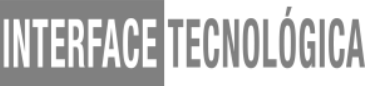

FEBRABAN - FEDERAÇÃO BRASILEIRA DE BANCOS. Canais de Atendimento dos Bancos. Disponível em: <https://portal.febraban.org.br/pagina/3055/30/pt-br/canais-deatendimento>. Acesso em: 12 fev. 2017. $21 \mathrm{~h} 10$

GIL, A. C. Como elabora projetos de pesquisa. 4. Ed.. São Paulo: Atlas, 2002.

GOODE, W. J.; HATT, P. K. Métodos em pesquisa social. 3. ed. São Paulo: Cia. Editora Nacional, 1969.

MAXIMIANO, A. C. A. Introdução à administração. $1^{\mathrm{a}}$ Ed. Compacta.4. reimpr. São Paulo/SP: Atlas, 2009.

OKINO, D. A. Gestão da cadeia de suprimentos aplicada à operação de numerário no Brasil. São Paulo/SP, FGV, 2010.

YIN, R. K. Case study research: design and methods. USA: Sage, 1989. 